\title{
Great Horned Owl
}

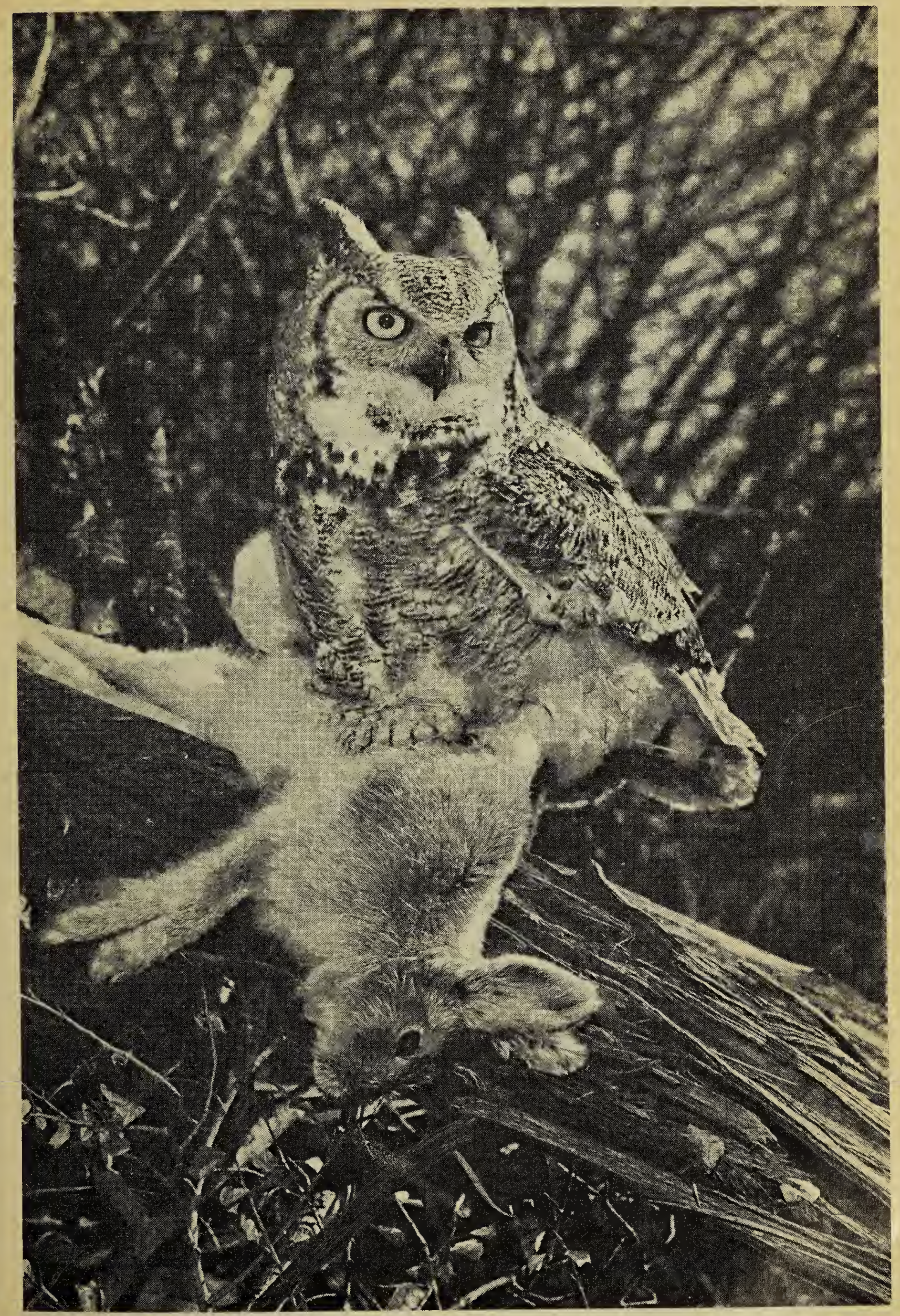

Photo by H. Dommasch and A. Dziadyk 


\title{
A Plea to Banders for Caution in Handling Great Horned Owls
}

\author{
By Dick Lumsden, Edmonton, Alberta
}

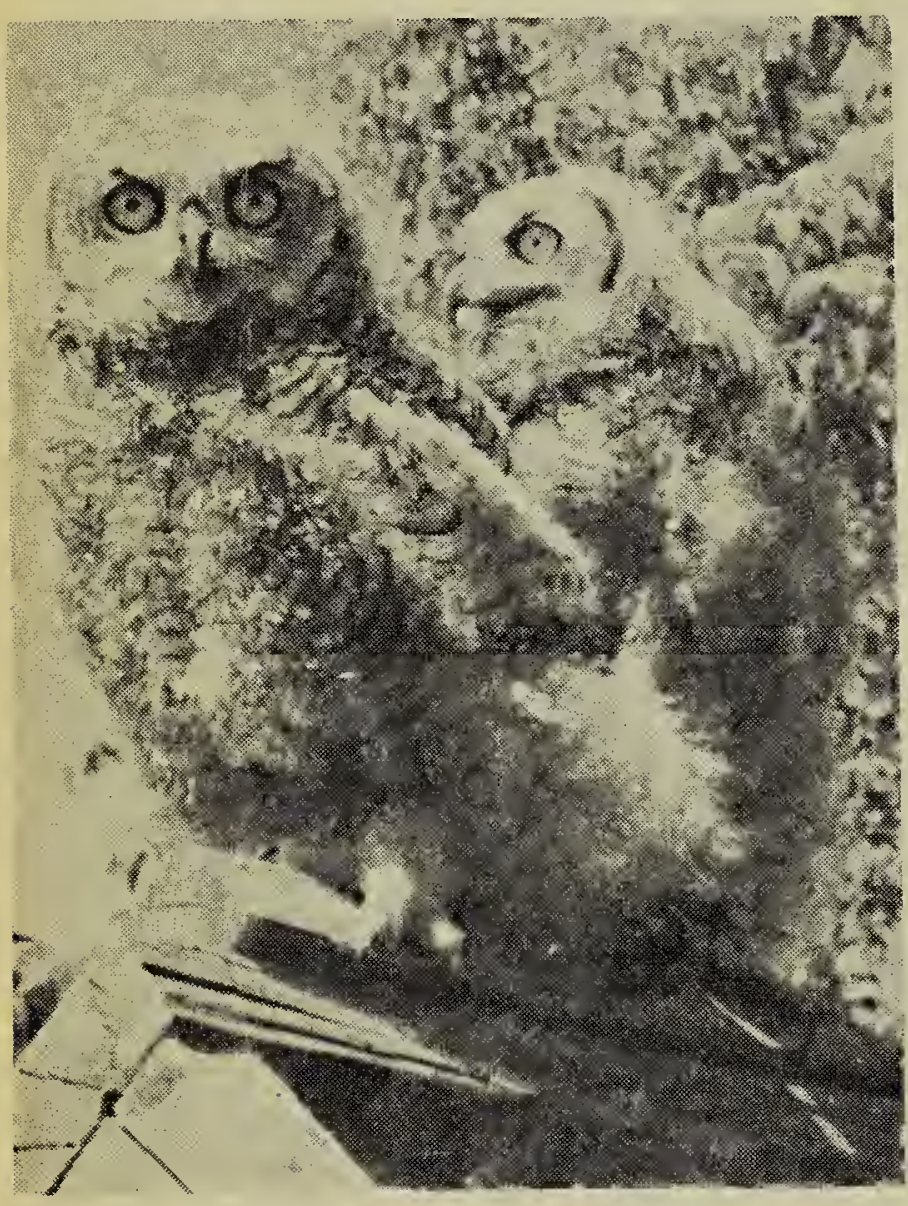

Photo by Dick Lumsden YOUNG HORNED OWLS

I have been a bird and mammal enthusiast for the past six years and have been particularly captivated by Alberta's winged predators, especially owls. In the past four years I have reared five homeless Great Horned Owls, six Burrowing Owls, two Sawwhet Owls, a Boreal Owl, a Longeared Owl, a Red-tailed Hawk, a Marsh Hawk, and have trained several falcons and hawks for $\mathrm{Al}$ Oeming.

Another activity I engage in is banding, and I am going to tell about an evening trip I made with three friends to a local Horned Owl's nest. At 7.30 on May 14 we arrived at the first nest and banded one young bird without a single attack from the mother owl, then set off for a second nest near Spruce Grove. We arrived at the base of the second nest at sundown (9.10 p.m.).

The bulky nest was situated at the top of a 50-foot balsam poplar in a large forested area of tangled wil- lows, spruce, tamarack and patches of muskeg. The parent birds could neither be seen or heard, so I decided to climb to the nest. I wore climbing spurs, a waist belt, a safety belt and a leather jacket, but neglected to wear a hait. Flastened to a clasp in the waist belt was a 60-foot length of rope attached to a small satchel to be used for lowering the owls so that they could be banded.

When I was half-way up the huge tree one of the three young owls plopped out of the nest and was promptly banded. I reached the nest and gently stuffed a plump young owl, about four weeks old, into the satchel. I lowered the bag carefully, avoiding intervening branches, and owl number two was banded and returned to the nest.

I threw down several pellets from the nest, which were later found to contain mainly Varying Hare $(70 \%)$, mouse $(20 \%)$ and weasel $(5 \%)$, as well as remains of freshly-killed Ruffed Grouse (1-3\%). Ruffed Grouse were very abundant in the surrounding bushland.

I then grabbed the third and last young owl, but my grip was awkward and I placed the owl on a nearby branch to get a better hold. It lost its balance and tumbled down to the top branch of a flimsy poplar directly below me. There it clung desperately with its already powerful claws.

Still there were no signs of the parent owls and a Saw-whet was melodiously piping in the distant spruces all the while. The top branches of the slim poplar below sagged under the young owl's twopound weight. One of my friends shook the tree vigorously and the young owl shot back and forth like a fly on the end of a mule-driver's whiplash.

Just then the mother owl flew in from the west with her mate trailing behind. Both alighted on the top branches of a balsam poplar 50 feet to the north of me. Mother owl's first impression of the situation enraged her thoroughly-one of her young on 
the ground, one being mistreated and threatened in the slender poplar tree, and only one left in the nesit. The lad shaking the tree stopped, climbed the tree, retrieved the young owl and number three was banded.

Meanwhile mother owl hooted ferociously in deep tones, and her vocal threats became more fearsome. Suddenly she flew in and slashed my left hand, then perched once more to the south as I was busily preparing to climb down.

Blackness had enveloped the spruce bush, but the horizon and silhouetted treetops were still visible. The big yellow eyes of the second adult owl looked fierce as W-H-I-S-H he rushed by. I turned my eyes away from the parent owls for five seconds to find the clasp on my safety belt so that I could climb down more quickly. When I looked up a black figure was speeding swiftly from the shadows and smashing into my face with her talons, her whole body's momentum behind them. One talon pierced my left eye, blinding me instanitly. It had only taken the owl two seconds to fly $\mathbf{5 0}$ feet from her aerial perch to strike me, and I had not seen her in time to defend myself.

One hour later in hospital a wellqualified surgeon sutured the laceration and told me that any vision in the injured eye would develop by the grace of God and not by his skill. After the first month in hospital vision had improved to about $5 \%$; today, on July 16, vision in the injured eye has improved greatly to about 20-25\%, with good peripheral vision. I have had to lead a quiet life during the past two months and of course I missed my Grade 12 finals.

From my experience, and in the besit interests of those who share my enthusiasm for winged predators, I make the following recommendations:

(1) Never climb a Horned Owl's nest at night, especially if young are present.

(2) When climbing up to a Horned Owl, Goshawk, Pigeon Hawk or even a Crow's nest wear a safety mask, either a hockey goalie's plastic mask or a strong-meshed fencer's mask.

(3) Wear a heavy pair of leather gloves, preferably welder's gloves used in falconry.

(4) Wear climbing spurs if necessary.

(5) Wear a tough leather jacket.

(6) Break off a branch on the way up to a Horned Owl's nest in order to strike the female if she attacks, as this will usually discourage further attacks.

Horned Owls disturbed at their nest by humans mean business, and their maternal instinct is so strong that they will risk their lives to protect their young. They are crafty in their attack strategy and may strike from unexpected angles, ripping at any flesh they can seize. The value of a mask for protection is thus immeasurable.

(Editor's Note: We are pleased to note that Dick's enthusiasm for wildlife has not waned in spite of this personal injury.)

\section{Hybrid Duck}

A challenging problem in identification was posed by the appearance of an unusual duck on Wascana Lake, June 1, 1959 (Blue Jay, XVII:98). The skin and carcass were sent from the Saskatchewan Museum of Natural History to Dr. Philip S. Humphrey of the Peabody Museum of Natural History at Yale University, who wrote in reply to Dr. Nero:

"I received the skin and carcass of the hybrid duck last week. It is certainly a very curious beast. I have examined it carefully and discussed the matter in detail with Dillon Rip- ley. He and I both agree that the bird can only be a Muscovy-Mallard hybrid. The fact that the bird is a female accounts for its small size. The bird clearly has far more Muscovy in it than Mallard, although the beak is more like that of a dabbling duck than that of a Muscovy. Quite frankly, detailed comparison of specimens did not enable me to tell whether the dabbling duck member of the cross was Mallard or Black. Our main evidence for thinking that it must have been a Mallard is distributional rather than morphological." 